\title{
The neuroscience of birth - and the case for Zero Separation
}

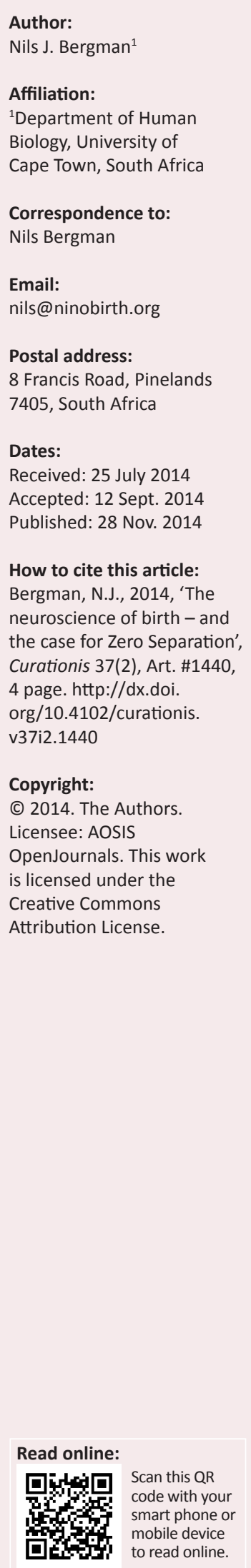

Currently, Western maternal and neonatal care are to a large extent based on routine separation of mother and infant. It is argued that there is no scientific rationale for this practice and a body of new knowledge now exists that makes a case for Zero Separation of mother and newborn. For the infant, the promotion of Zero Separation is based on the need for maternal sensory inputs that regulate the physiology of the newborn. There are harmful effects of dysregulation and subsequent epigenetic changes caused by separation. Skin-to-skin contact is the antithesis to such separation; the mother's body is the biologically 'normal' place of care, supporting better outcomes both for normal healthy babies and for the smallest preterm infants. In the mother, there are needed neural processes that ensure enhanced reproductive fitness, including behavioural changes (e.g. bonding and protection) and improved lactation, which are supported by the practice of Zero Separation. Zero Separation of mother and newborn should thus be maintained at all costs within health services.

\section{Introduction}

\section{Problem statement}

Until recently, the standard belief about the newborn brain was that it was extremely immature at birth. It was believed that maturation was primarily a genetically guided process and therefore relatively impervious to influence by early care at birth and inevitable adverse experiences. It was believed that mothers had negligible influence on their newborns' brains or bodies and that the important thing was to ensure newborn survival. There was a legacy of high maternal mortality, so childbirth was regarded as extremely dangerous and required management by specialists that ensured survival. In the process, success became measured largely by survival itself, not by quality of survival or any other behavioural or social outcomes. Over the last 100 years, this world view has shaped the way in which health services are designed and operated. New ideas that might possibly undermine the good results that modern care has achieved are often met with resistance.

\section{Aims}

The above beliefs and ideas about childbirth are not supported by 21st century neuroscience or by evidence-based medicine. This brief scientific report provides a critical examination of the current gap between latest evidence and current practice in newborn care.

\section{Trends}

Early childhood development and policy makers refer to the 'first 1000 days' as the first two years of life, as well as the 270 days preceding birth (Panter-Brick \& Leckman 2013). The human newborn is born with a relatively small brain, but science has shown that it is perfectly wired and competent for early extra-uterine life (Schore 2001a; Winberg 2005). A human will never be as alert as after a vaginal birth: noradrenalin wakes up the brain and is 10 times higher at birth than ever again (Lagercrantz \& Bistoletti 1977). High levels of noradrenalin activate the lungs and, more importantly, ensure early bonding with the mother (Ross \& Young 2009). The mother's smell (Porter 1998), contact and warmth 'fire' a pathway from the baby's amygdala to its frontal lobe (Bartocci et al. 2000), which connects the newborn's emotional and social brain circuits (Nelson \& Panksepp 1998). Whilst genes have made this possible (Lagercrantz 1996), the experience of a mother's constant and uninterrupted physical presence make it happen (Hofer 1994). It used to be asked whether 'nature or nurture drove development; more recently it was believed that it was nature and nurture AND niche' - with niche being the environment - that did so. The current view is to regard both nurture and niche as environment; nature's gene effects are multiplied in their interaction with this environment (commonly written GxE) (Caspi et al. 2010). 


\section{The case for Zero Separation}

Is the safest place for a newborn the observation nursery, separated from its mother? The Cochrane review on early skin-to-skin contact (SSC) for healthy newborns and their mothers (Moore et al. 2012) finds strong evidence that SSC produces improved physiological regulation and increases breastfeeding rates. Another Cochrane Review on the Kangaroo Mother Care (KMC) strategy which includes SSC, breastfeeding and early discharge (World Health Organization [WHO] 2003), concludes that KMC lowers mortality (Conde-Agudelo, Belizán \& Diaz-Rossello 2011). Premature babies are, in many hospitals, believed to be unstable, thus holding and touch is discouraged. Findings from a randomised controlled trial published 10 years ago indicate, however, that low-birth-weight newborns stabilised because they were not separated from their mothers. In contrast, preterm babies became increasingly unstable during their first six hours of life in optimal incubator care (Bergman, Linley \& Fawcus 2004). Why then do private and public hospital staff still believe that the mother's body is a dangerous place for newborns, when research demonstrates that premature babies become unstable because their mothers are not holding them, that is to say, because of maternal-infant separation (Bergman et al. 2004)?

A common view of a newborn is that it lies in its bed, where it either cries or sleeps; and swaddling is helpful for stopping its crying. Crying is said to be good, helping to fill the lungs with air. Modern neuroscience, however, does not support this view. The science behind reproductive biology is that all of a mother's body sensations help control all of the different parts of the physiology of the baby (Hofer 2005); this is called regulation. Prolonged maternal regulation results in healthy physiological set-points (Hofer 2005), mediated by epigenetic settings that wire midbrain neural circuits (Meaney \& Szyf 2005). Babies cry because of the absence of the maternal sensory regulators: they are experiencing dysregulation (Christensson et al. 1995; Hofer 2005). This shuts off the baby's growth hormone and switches on cortisol (Hofer 2005). Cortisol diverts all the calories and other neurological resources to ensuring survival, so that homeostasis is re-established, but at the cost of growth. Such infants do have 'stable vital signs', but the energy consumed to achieve this homeostasis is not measured (McEwen \& Seeman 1999). When the mother provides regulation through her own body, all of the baby's energy is available for development.

In a study of two-day-old healthy babies sleeping alternatively in cots and in SSC (their own controls), cot sleeping showed three times higher autonomic nervous system (ANS) activation compared with SSC (Morgan, Horn \& Bergman 2011). It is now known that more calories are required with higher ANS activity; this is accompanied by high cortisol levels. When cortisol is doing the regulating, less efficient homeostatic set-points are being programmed in the physiology of the baby. These set-points remain for life (Hochberg et al. 2011). The most well established effect of this re-programming is obesity (Stettler et al. 2005), but hypertension, high cholesterol and diabetes may become likely health outcomes because of such changes (Coe \& Lubach 2008). Furthermore, the infant connection of amygdala to frontal lobe is weakened (Schore 2001b) and the capacity for trust is compromised when the infant's basic needs are not met (Ross \& Young 2009).

The swaddled and separated baby lies still with its eyes closed, and is believed to be sleeping. A study on autonomic activation (Morgan et al. 2011), showed that quiet sleep was reduced by $86 \%$ in separated babies and their sleep cycling was almost abolished. There were also specific autonomic patterns in separated babies, which match perfectly those described as 'threat responses' found in abused children (Perry et al. 1995). The first sign of perceived threat results in vigilance, where crying has survival value since the perceived threat is further away than the mother. When the perceived threat is closer than the mother, or if the mother is not responding, a cry response would, however, increase danger, thus a state of freeze follows (Misslin 2003). This 'freeze state' is produced by intense and total autonomic activation, with profound avoidance activation on electroencephalogram (Jones, McFall \& Diego 2004). Such babies lie absolutely still, absolutely quiet, with eyes firmly closed. This is believed to be sleep! It is however a state of high arousal, also called 'fear-terror' (Perry et al. 1995). When this state is prolonged, cortisol may initiate harmful changes that can affect the individual across its lifespan.

Whilst survival rates are important, it is the quality of survival that actually matters. This is specifically true for preterm infants that spend weeks in separation. It has been shown that there is a poor quality of survival with respect to their immunity (Baron et al. 2011; Bird et al. 2010), IQ and scholastic achievement (Jain 2008; Morse et al. 2009). SSC with Zero Separation is the biological normal (default) and is the one intervention above any other that can improve quality of survival.

\section{The impact of Zero Separation on the mother}

Nursing practices also ensure the mother's safety, but many procedures and restrictions have no evidence base. Over recent years, procedures have been tested methodically in randomised controlled trials and have been shown to be unhelpful or even harmful. Examples of such procedures include shaving, episiotomy, giving birth in lithotomy, continuous cardiotocograph use and starving during labour (WHO 2014). Whilst there have been changes, health professionals still maintain control of the whole birth experience; the mother is not allowed this basic right (WHO 2014).

A new mother is often still coerced or encouraged into thinking that she needs 'to rest and be alone' after birth, that this is good for her and that it is safest and best for her baby to be in the hospital nursery. Reproductive biology affirms that there are critical periods that operate in the newborn (Lee 2003), but equally so in the mother. The stimulations 
the newborn provides to the mother, including eye contact, nipple stimulations and sounds, all work together to trigger new neural circuits in the mother. One of these is an oxytocin effect in the anterior cingulate gyrus (Uvnäs-Moberg 2003), which produces 'ferocity of defence of young' (HahnHolbrook et al. 2011; Leng, Meddle \& Douglas 2008). The window for this effect is only a few hours (Uvnäs- Moberg 2003). Early suckling produces prolactin which ensures that mammogenesis is optimal (Uvnäs-Moberg et al. 1990); the window for this is two days. Thus, successful breastfeeding requires Zero Separation. Many other effects are taking place, but suffice it to say, it is a huge disservice to mothers when their newborns are removed.

Whilst mothers themselves need observation and care in order to prevent complications during and after childbirth, this author believes that current care must accommodate the new understanding of reproductive biology and developmental neuroscience. Maternal and fetal outcomes are profoundly improved when doula care is provided (American College of Obstetricians and Gynecologists 2014) along with 'natural birth' (Mercer et al. 2007; Smith, Plaat \& Fisk 2008), as well as when the ecologically-valid environment that produces the ' $G \times E^{\prime}$ described earlier is ensured. Although the technology and skills available for newborn and preterm care are wonderful, they do not require separation; they should instead be applied to the right place, the mother's chest (Phillips 2013; White 2004). In this way, maternal, physiological regulation will be working in synergy with the baby's ANS, the need for technology will be lessened and the intensity thereof can be reduced, with better outcomes.

The essential requirement is maternal-infant 'togetherness', the first part of which is SSC, starting from the moment of birth and Zero Separation (Bergman \& Bergman 2013). Achieving 'togetherness' also requires that the father does SSC (Erlandsson et al. 2007; Gloppestad 1998). Space thus needs to be provided for both mother and father to care for their baby. Broader social support is needed, not the 'one size fits all' and 'no space for father' that institutional and impersonal service often codify so rigidly.

\section{Conclusion}

The one intervention above any other that would improve neonatal and maternal outcomes is Zero Separation for the first day of every newborn's life.

\section{Acknowledgements Competing interests}

The author declares that he has no financial or personal relationship(s) that may have inappropriately influenced him in writing this article.

\section{References}

American College of Obstetricians and Gynecologists, 2014, 'Obstetric care consensus no. 1: Safe prevention of the primary cesarean delivery' Obstetrics and Gynecology 123(3), 693-711. http://dx.doi.org/10.1097/01. AOG.0000444441.04111.1d
Baron, I.S., Erickson, K., Ahronovich, M.D., Baker, R. \& Litman, F.R., 2011, 'Cognitive deficit in preschoolers born late-preterm', Early Human Development 87(2), 115-119. http://dx.doi.org/10.1016/j.earlhumdev.2010.11.010

Bartocci, M., Winberg, J., Ruggiero, C., Bergqvist, L.L., Serra, G. \& Lagercrantz, H., 2000, 'Activation of olfactory cortex in newborn infants after odor stimulation: A functional near-infrared spectroscopy study', Pediatric Research 48(1), 18-23. http://dx.doi.org/10.1203/00006450-200007000-00006

Bergman, J. \& Bergman, N., 2013, 'Whose choice? Advocating birthing practices according to baby's biological needs', The Journal of Perinatal Education 22(1) 8-13. http://dx.doi.org/10.1891/1058-1243.22.1.8

Bergman, N.J., Linley, L.L. \& Fawcus, S.R., 2004, 'Randomized controlled trial of skin-to-skin contact from birth versus conventional incubator for physiological stabilization in 1200- to 2199-gram newborns', Acta Paediatrica 93(6), 779-785. http://dx.doi.org/10.1111/j.1651-2227.2004.tb03018.x

Bird, T.M., Bronstein, J.M., Hall, R.W., Lowery, C.L., Nugent, R. \& Mays, G.P., 2010, 'Late preterm infants: Birth outcomes and health care utilization in the first year', Pediatrics 126(2), e311-e319. http://dx.doi.org/10.1542/peds.2009-2869

Caspi, A., Hariri, A.R., Holmes, A., Uher, R. \& Moffitt, T.E., 2010, 'Genetic sensitivity to the environment: The case of the serotonin transporter gene and its implications for studying complex diseases and traits', The American Journal of Psychiatry 167(5), 509-527. http://dx.doi.org/10.1176/appi.ajp.2010.09101452

Christensson, K., Cabrera, T., Christensson, E., Uvnäs-Moberg, K. \& Winberg J., 1995, 'Separation distress call in the human neonate in the absence of maternal body contact' Acta Paediatrica 84(5), 468-473, http://dx.doi. org/10.1111/j.1651-2227.1995.tb13676.x

Coe, C.L. \& Lubach, G.R., 2008, 'Fetal programming: Prenatal origins of health and illness', Current Directions in Psychological Science 17(1), 36-41. http://dx.doi. org/10.1111/j.1467-8721.2008.00544.x

Conde-Agudelo, A., Belizán, J.M. \& Diaz-Rossello, J., 2011, 'Kangaroo mother care to reduce morbidity and mortality in low birthweight infants', The Cochrane Database of Systematic Reviews 3, CD002771.

Erlandsson, K., Dsilna, A., Fagerberg, I. \& Christensson, K., 2007, 'Skin-to-skin care with the father after cesarean birth and its effect on newborn crying and prefeeding behavior', Birth 34(2), 105-114. http://dx.doi.org/10.1111/j.1523536X.2007.00162.x

Gloppestad, K., 1998, 'Experiences of maternal love and paternal love when preterm infants were held skin to skin and wrapped in blankets: Differences between two types of holding [Norwegian]', Vård i Norden 47(1), 23-30.

Hahn-Holbrook, J., Holt-Lunstad, J., Holbrook, C., Coyne, S.M. \& Lawson, E.T., 2011, 'Maternal defense: Breast feeding increases aggression by
reducing stress', Psychological Science 22(10), 1288-1295. http://dx.doi. reducing stress', Psychological
org/10.1177/0956797611420729

Hochberg, Z., Feil, R., Constancia, M., Fraga, M., Junien, C., Carel, J.C. et al., 2011 'Child health, developmental plasticity, and epigenetic programming', Endocrine Reviews 32(2), 159-224. http://dx.doi.org/10.1210/er.2009-0039

Hofer, M.A., 1994, 'Early relationships as regulators of infant physiology and behavior' Acta Paediatrica 397, 9-18. http://dx.doi.org/10.1111/j.1651-2227.1994. tb13260.x

Hofer, M.A., 2005, 'The psychobiology of early attachment', Clinical Neuroscience Research 4(5-6), 291-300. http://dx.doi.org/10.1016/j.cnr.2005.03.007

Jain, L., 2008, 'School outcome in late preterm infants: A cause for concern', The Journal of Pediatrics 153(1), 5-6. http://dx.doi.org/10.1016/j.jpeds.2008.03.001

Jones, N.A., McFall, B.A. \& Diego, M.A., 2004, 'Patterns of brain electrical activity in infants of depressed mothers who breastfeed and bottle feed: The mediating role of infant temperament', Biological Psychology 67(1-2), 103-124. http://dx.doi. org/10.1016/j.biopsycho.2004.03.010

Lagercrantz, H., 1996, 'Stress, arousal, and gene activation at birth', Physiology 11(5), 214-218.

Lagercrantz, H. \& Bistoletti, H., 1977, 'Catecholamine release in the newborn infant at birth', Pediatric Research 11(8), 889-893. http://dx.doi.org/10.1203/00006450197708000-00007

Lee, C., 2003, 'Bonding', Pediatrics in Review 24(8), 289-290. http://dx.doi. org/10.1542/pir.24-8-289

Leng, G., Meddle, S.L. \& Douglas, A.J., 2008, 'Oxytocin and the maternal brain', Current Opinion in Pharmacology 8(6), 731-734. http://dx.doi.org/10.1016/j. coph.2008.07.001

McEwen, B.S. \& Seeman, T., 1999, 'Protective and damaging effects of mediators of stress. Elaborating and testing the concepts of allostasis and allostatic of stress. Elaborating and testing the concepts of allostasis and allostatic
load', Annals of the New York Academy of Sciences 896, 30-47. http://dx.doi. load', Annals of the New York Academy of
org/10.1111/j.1749-6632.1999.tb08103.x

Meaney, M.J. \& Szyf, M., 2005, 'Maternal care as a model for experience-dependent chromatin plasticity?', Trends in Neurosciences 28(9), 456-463. http://dx.doi. org/10.1016/j.tins.2005.07.006

Mercer, J.S., Erickson-Owens, D.A., Graves, B. \& Haley, M.M., 2007, 'Evidence-based practices for the fetal to newborn transition', Journal of Midwifery \& Women's Health 52(3), 262-272. http://dx.doi.org/10.1016/j.jmwh.2007.01.005

Misslin, R., 2003, 'The defense system of fear: behavior and neurocircuitry', Neurophysiologie Clinique 33(2), 55-66. http://dx.doi.org/10.1016/S09877053(03)00009-1

Moore, E.R., Anderson, G.C., Bergman, N. \& Dowswell, T., 2012, 'Early skin-to-skin contact for mothers and their healthy newborn infants', The Cochrane Database of Systematic Reviews 5, CD003519.

Morgan, B.E., Horn, A.R. \& Bergman, N.J., 2011, 'Should neonates sleep alone?', Biological Psychiatry 70(9), 817-825. 'http://dx.doi.org/10.1016/j. biopsych.2011.06.018 
Morse, S.B., Zheng, H., Tang, Y. \& Roth, J., 2009, 'Early school-age outcomes of late preterm infants', Pediatrics 123(4), e622-e629. http://dx.doi.org/10.1542/ peds.2008-1405

Nelson, E.E. \& Panksepp, J., 1998, 'Brain substrates of infant-mother attachment: contributions of opioids, oxytocin, and norepinephrine', Neuroscience and Biobehavioral Reviews 22(3), 437-452. http://dx.doi.org/10.1016/S01497634(97)00052-3

Panter-Brick, C. \& Leckman, J.F., 2013, 'Editorial commentary: resilience in child development - interconnected pathways to wellbeing', The Journal of Child Psychology and Psychiatry 54(4), 333-336. http://dx.doi.org/10.1111/jcpp.12057

Perry, B.D., Pollard, R.A., Blakley, T.L., Baker, W.L. \& Vigilante, D., 1995, 'Childhood trauma, the neurobiology of adaptation, and "use-dependent" development of the brain. How "states" become "traits"', Infant Mental Health Journal 16(4), 271-291. http://dx.doi.org/10.1002/1097-0355(199524)16:4<271::AIDIMHJ2280160404>3.0.CO;2-B

Phillips, R., 2013, 'The sacred hour: Uninterrupted skin-to-skin contact immediately after birth', Newborn \& Infant Nursing Reviews 13(2), 67-72. http://dx.doi. org/10.1053/j.nainr.2013.04.001

Porter, R.H., 1998, 'Olfaction and human kin recognition', Genetica 104(3), 259-263. http://dx.doi.org/10.1023/A:1026404319384

Ross, H.E. \& Young, L.J., 2009, 'Oxytocin and the neural mechanisms regulating social cognition and affiliative behavior', Frontiers in Neuroendocrinology 30(4), 534-547. http://dx.doi.org/10.1016/j.yfrne.2009.05.004

Schore, A.N., 2001a, 'Effects of a secure attachment relationship on right brain development, affect regulation, and infant mental health', Infant Mental Health Journal 22(1-2), 7-66. http://dx.doi.org/10.1002/10970355(200101/04)22:1<7::AID-IMHJ2>3.0.CO;2-N
Schore, A.N., 2001b, 'The effects of early relational trauma on right brain development, affect regulation, and infant mental health', Infant Mental Health Journal 22(1-2), 201-269. http://dx.doi.org/10.1002/10970355(200101/04)22:1<201::AID-IMHJ8>3.0.CO;2-9

Smith, J., Plaat, F. \& Fisk, N.M., 2008, 'The natural caesarean: A woman-centred technique', British Journal of Obstetrics and Gynaecology 115(8), 1037-1042. http://dx.doi.org/10.1111/j.1471-0528.2008.01777.x

Stettler, N., Stallings, V.A., Troxel, A.B., Zhao, J., Schinnar, R., Nelson, S.E. et al., 2005 'Weight gain in the first week of life and overweight in adulthood: A cohort study of European American subjects fed infant formula', Circulation 111(15), 1897-1903. http://dx.doi.org/10.1161/01.CIR.0000161797.67671.A7

Uvnäs-Moberg, K., 2003, The oxytocin factor: Tapping the hormone of calm, love, and healing, 2nd edn., Da Capo Press, Cambridge, MA.

Uvnäs-Moberg, K., Widström, A-M., Nissen, E. \& Björvell, H., 1990, 'Personality traits in women 4 days postpartum and their correlation with plasma levels of oxytocin and prolactin', Journal of Psychosomatic Obstetrics \& Gynaecology 11(4), 261and prolactin', Journal of Psychosomatic Obstetrics \&
273. http://dx.doi.org/10.3109/01674829009084422

White, R.D., 2004, 'Mothers' arms - the past and future locus of neonatal care?', Clinics in Perinatology 31(2), 383-387, ix. http://dx.doi.org/10.1016/j. clp.2004.04.009

Winberg, J., 2005, 'Mother and newborn baby: Mutual regulation of physiology and behavior - a selective review', Developmental Psychobiology 47(3), 217-229. http://dx.doi.org/10.1002/dev.20094

World Health Organization, 2003, Kangaroo mother care: a practical guide, WHO, Geneva.

World Health Organization, 2014, The WHO Reproductive Health Library, viewed 30 July 2014, from http://apps.who.int/rhl/en/ 